\title{
EPSL
}

Earth and Planetary Science Letters 164 (1998) 379-385

\section{Magnetic telechemistry and magmatic segmentation on the Southern East Pacific Rise}

\author{
J. Gee ${ }^{\mathrm{a}, *}$, D.V. Kent ${ }^{\mathrm{b}, 1}$ \\ a Scripps Institution of Oceanography, La Jolla, CA 92093, USA \\ ${ }^{b}$ Lamont-Doherty Earth Observatory, Palisades, NY 10964, USA
}

Received 27 April 1998; revised version received 27 July 1998; accepted 8 September 1998

\begin{abstract}
Results from axial dredges and a profile inversion of magnetic anomaly data along the axis of the East Pacific Rise (EPR) at $13-23^{\circ} \mathrm{S}$ provide an estimate of the average degree of fractionation for the extrusive layer at this ultrafast-spreading $\left(\sim 145 \mathrm{~mm} / \mathrm{yr}\right.$ full rate) ridge. We find a high correlation $(R=0.81)$ between dredge mean $\mathrm{FeO}^{*}$ (total iron as $\mathrm{FeO}$ ) and natural remanence for 34 axial dredges with multiple samples having coincident geochemical and magnetic data. We attribute this good correlation to detailed sampling spanning the full range of cooling-related magnetization changes within a flow and to the young age (0-6 ka) of these axial samples, which effectively minimizes time-dependent magnetization changes due to geomagnetic intensity or alteration. A composite axial magnetic anomaly profile shows large amplitude (up to $400 \mathrm{nT}$ ) fluctuations with wavelengths of 50-200 km, which theoretical considerations suggest can reliably be related to the magnetization directly beneath the ship. For much of the southern EPR, seismic data provide independent limits on the axial thickness $(259 \pm 55 \mathrm{~m})$ and the pattern of off-axis thickening of the extrusive magnetic source layer. These data also provide evidence for an axial magma lens that effectively eliminates anomaly contributions from deeper magnetic sources. Inversion of the axial magnetic anomaly data utilizing these geophysical constraints yields a magnetization solution which, through use of the regression relating $\mathrm{FeO}^{*}$ and natural remanence, may be related to the average degree of differentiation of the extrusive source layer. The magnetic data reveal a pattern of magmatic segmentation that closely parallels the tectonic segmentation of the ridge, suggesting that magma supply may be an important control on the average degree of differentiation of the extrusive layer. (c) 1998 Elsevier Science B.V. All rights reserved.
\end{abstract}

Keywords: East Pacific Rise; magnetic anomalies; iron; magmatic differentiation

Since a causal relationship was first suggested between the presence of iron-rich lavas and high amplitude magnetic anomalies [1], the magnetic tele-

\footnotetext{
*Corresponding author. Tel.: +1 619534 4707; Fax: +1 619 534-0784; E-mail: jsgee@ucsd.edu

${ }^{1}$ Also at: Department of Geological Sciences, Rutgers University, Piscataway, NJ 08854, USA.
}

chemistry concept has been used to delineate regions of presumed differentiated lavas [2]. Such differentiated ferrobasalts and rarer silica rich lavas $\left(\mathrm{FeO}^{*}\right.$ $>12 \%$ ) are commonly associated with ridge crest discontinuities, where low magma supply rates and moderate cooling rates allow enhanced degrees of fractionation in shallow, ephemeral magma bodies $[3,4]$. Although volumetrically minor [5], these com- 
positions reflect processes of low pressure crystal fractionation and associated iron enrichment that are ubiquitous in mid-ocean ridge basalt (MORB) suites. Variations in the degree of fractionation along axis therefore potentially provide important information on the geometry of melt injection and redistribution at mid-ocean ridges [6-8]. Here, we use axial magnetic anomalies to estimate the integrated degree of fractionation of the extrusive layer along the geophysically well-constrained East Pacific Rise (EPR) from $13-23^{\circ} \mathrm{S}$. The magnetic data reveal a magmatic segmentation that closely parallels the tectonic segmentation of the ridge, suggesting that magma supply may be an important, if not the dominant, control on the average degree of differentiation of the extrusive layer.

Magnetic telechemistry postulates that iron enrichment in MORB is accompanied by increased abundance of titanomagnetite, resulting in higher natural remanent magnetization (NRM) and thus in enhanced magnetic anomaly amplitudes. Despite the qualitative success of magnetic telechemistry in delineating iron-rich regions of the crust [2,9-13], more quantitative applications have been hindered by the difficulty in demonstrating the direct link between iron enrichment and higher NRM [14], the only relevant parameter for comparison with anomaly amplitudes, as well as by uncertainties in the geometry of the magnetic source layer.
In a recent study of more than 250 samples ( $\sim 2100$ specimens) from 50 axial dredge hauls along the ultrafast spreading $(\sim 145 \mathrm{~mm} / \mathrm{yr}$ full rate) southern EPR [15], we have documented a higher degree of correlation between $\mathrm{FeO}^{*}$ and NRM than in any previous study. In our study, detailed sampling perpendicular to the chilled margin allowed robust characterization of the average remanence of samples from the southern EPR, accounting in part for the substantial (up to order of magnitude) variation in magnetic properties within a flow/pillow $[15,16]$. As importantly, the young age (U-series ages 0-6 $\mathrm{ka} ;[17])$ of these axial dredges effectively minimized magnetization differences due to time-dependent changes in geomagnetic intensity or alteration. For the 34 dredges with three or more samples having coincident geochemical and magnetic data, we find a high degree of correlation $(R=0.81)$ between dredge mean $\mathrm{FeO}^{*}$ and the dredge mean NRM (Fig. 1). These results indicate that a substantial portion, perhaps as much as two-thirds, of the magnetization variation in comparable age MORB samples may be related to differences in geochemistry.

A composite sea surface magnetic anomaly profile along the EPR axis $\left(13-23^{\circ} \mathrm{S}\right)$ reveals large amplitude variations (Fig. 2a), the largest of which $(>400 \mathrm{nT})$ are comparable to or even larger than the amplitudes at major magnetic reversal boundaries. The close correspondence of axial anomaly data

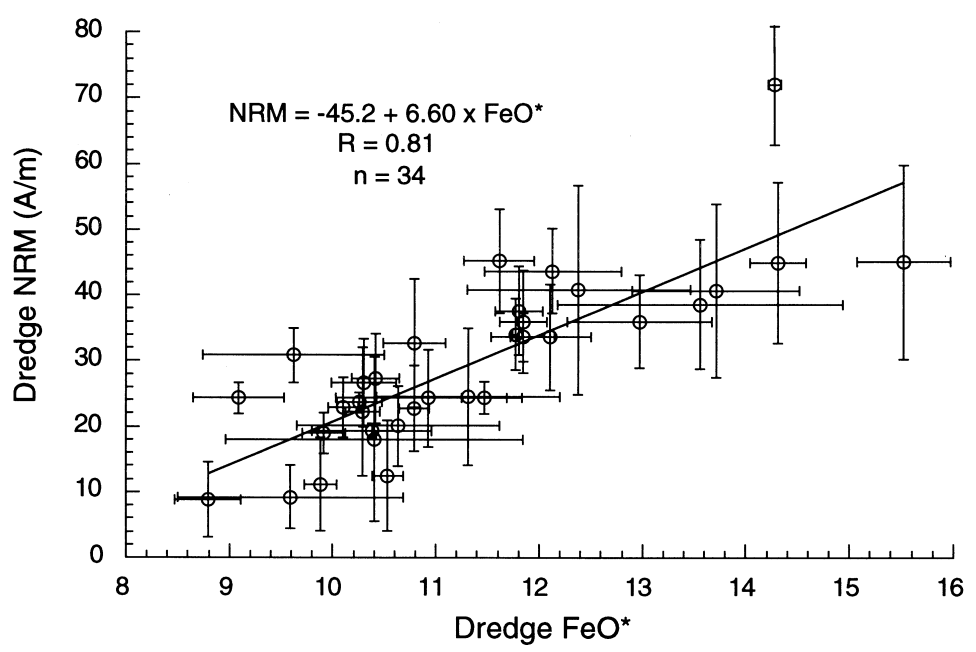

Fig. 1. Variation in natural remanent magnetization $(N R M)$ as a function of $\mathrm{FeO}^{*}$ (total $\mathrm{Fe}$ as $\mathrm{FeO}$ ) for dredges from the southern EPR. NRM values represent the arithmetic mean intensity $( \pm 1 \sigma)$ of three of more flows/pillows, each with multiple subspecimens [15]. Dredge mean $\mathrm{FeO}^{*}$ content (with $1 \sigma$ error) calculated from microprobe analysis of glass chips [8] from samples used for magnetic study. 


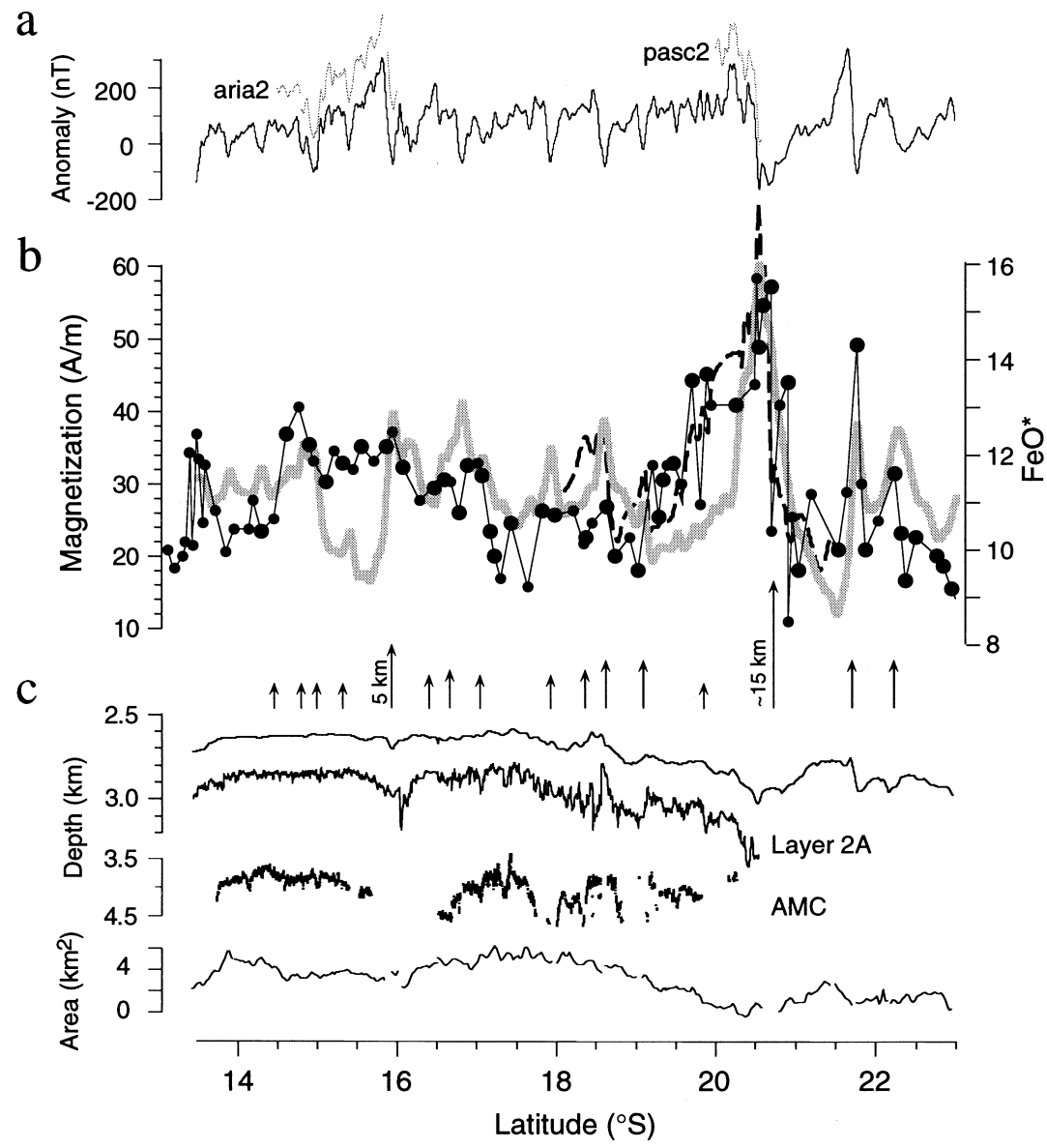

Fig. 2. Magnetic and geochemical variations along the axis of the southern EPR. (a) Composite axial magnetic anomaly (prior to reduction to pole) constructed primarily from e9102 cruise, corroborated and extended with data from aria2 and pasc2 cruises. Representative segments from the latter two cruises (light grey lines; offset by $150 \mathrm{nT}$ for clarity) illustrate reproducibility of anomaly pattern. All anomalies recalculated using the appropriate Definitive Geomagnetic Reference Field model. Remaining small discrepancies (typically $<50 \mathrm{nT}$ ) may be attributed to diurnal field variations. (b) Magnetization inferred from profile inversion (heavy grey line) and grid inversion (dashed, both left scale) is compared to $\mathrm{FeO}^{*}$ content [8] (filled circles, with larger circles indicating dredges for which sample magnetizations are available [15]), with the scaling and offset between the axes determined by the regression result from Fig. 1. Prior to inversion, the axial anomaly was reduced to pole in $1^{\circ}$ latitude increments to allow for variable phase shift resulting from differences in ridge azimuth and magnetic latitude along length of profile. Profile inversion of the composite axial anomaly uses an effective source thickness of $375 \mathrm{~m}$, corresponding to an extrusive layer that thickens from $250 \mathrm{~m}$ to $500 \mathrm{~m}$ within approximately $2.5 \mathrm{~km}$ of the ridge crest. A cosine-tapered band-pass filter was applied where wavelengths $<10 \mathrm{~km}$ and $>600 \mathrm{~km}$ were cut and wavelengths $>20 \mathrm{~km}$ and $<300 \mathrm{~km}$ were passed unattenuated. Spectral inversion of the axial anomaly data explicitly including the off-axis thickening of 2A yields essentially the same magnetization contrasts [26]. Our axial magnetization solution also yields a pattern similar to that obtained from previous inversions of grid magnetic data [33,35]; the slight offset between the grid inversion solution (scaled for 500 $\mathrm{m}$ source layer thickness; finer dashed line) and the profile inversion may be related to longer wavelength features in the magnetic annihilator. (c) Along-axis variations in bathymetry, seismic Layer 2A thickness, and depth to axial magma chamber [21] used to constrain magnetic source layer. Arrows depict axial discontinuities with arrow length proportional to the magnitude of the offset. Ridge cross sectional area is shown for comparison [37].

from three separate multibeam-navigated cruises suggests that navigational uncertainties are unlikely to account for any significant along-axis amplitude variations (Fig. 2a). Moreover, much of the anomaly data used in our analysis was acquired during a seismic survey which imaged an axial magma lens 
over most of the ridge segment [18]. Since ridge perpendicular seismic profiles indicate the width of the axial magma lens is $<1 \mathrm{~km}$ [19], the presence of a magma chamber reflector provides additional support for minimal navigation errors. The remaining small (typically $<50 \mathrm{nT}$ ) discrepancies between the profiles may plausibly be attributed to diurnal geomagnetic variations.

The large axial amplitude variations must therefore reflect both changes in the geometry of the source layer as well as along-axis fluctuations in NRM intensity. In contrast to most other ridge segments, the geometry of the magnetic source layer along the southern EPR is well constrained by multichannel seismic data (Fig. 2c). Elevated crustal temperatures associated with a shallow axial magma lens [18] effectively eliminate any magnetic contribution from the gabbroic layer and further reduce any signal from the weakly magnetized sheeted dikes [20]. In addition, the seismic data indicate a remarkably uniform axial thickness ( $259 \pm 55 \mathrm{~m}$; [21]) for seismic Layer 2A. Ridge perpendicular seismic profiles also indicate that Layer 2A typically increases in thickness by a factor of 2-3 over a distance of 2-3 km from the ridge axis $[19,22]$. We use the near constant along-axis thickness of Layer 2A, nominally corresponding to the extrusive layer $[23,24]$, as well as its pattern of off-axis thickening to define the magnetic source layer. Together with systematic axial sampling [8] and the favorable ridge azimuth, this ridge segment therefore provides an unique opportunity for a stringent application of magnetic telechemistry.

We performed a profile inversion of the composite axial anomaly data to facilitate comparison with the geochemical data from the southern EPR. The resulting inversion solution (Fig. $2 \mathrm{~b}$ ) provides an estimate of axial magnetization variations for a $250 \mathrm{~m}$ extrusive source layer that doubles in thickness by $2.5 \mathrm{~km}$ off-axis. The magnitude of the magnetization contrast along axis (maximum $\sim 50 \mathrm{~A} / \mathrm{m}$ ) is nearly identical to the range of NRM intensities observed in axial samples from the southern EPR (Fig. 1); however, the zero level of the inversion solution is poorly defined by the axial anomaly alone. The zero level was determined by addition of magnetic annihilator [25], here essentially equivalent to a DC shift of the magnetization solution, sufficient to produce strictly positive magnetizations compatible with the lowest zero-age magnetizations $(\sim 10 \mathrm{~A} / \mathrm{m})$ measured along the southern EPR [15].

For comparison with the inversion solution, we calculated equivalent NRM values from the mean $\mathrm{FeO}^{*}$ content of each dredge [8] using the relationship presented in Fig. 1. The overall similarity between the two data sets (Fig. 2b), including where some smaller scale features in the inversion solution are paralleled by fluctuations in the geochemical data (e.g., low near $17.3^{\circ} \mathrm{S}$, highs at $21.8^{\circ} \mathrm{S}$ and $22.2^{\circ} \mathrm{S}$ ), provides confirmation of the link between geochemistry and anomaly amplitude predicted by the magnetic telechemistry hypothesis.

The observed axial magnetic anomaly represents the linear superposition of contributions from all magnetized bodies in the source region, i.e. all flow units in the extrusive layer. Given the causal (linear) relationship between $\mathrm{FeO}^{*}$ and representative magnetization of zero age lavas [15], we therefore expect close agreement between the axial magnetization solution and surficial samples from a geochemically uniform extrusive layer. Fine scale discrepancies between our inversion solution and the magnetization inferred from surficial sample geochemistry may simply reflect geochemical variations at wavelengths to which the axial sea surface anomaly is insensitive. For a magnetic profile along axis, Parker [26] has shown a high coherence $\left(\gamma^{2}>0.75\right.$ for wavelengths above $50 \mathrm{~km}$ ) between the axial anomaly and the magnetization directly beneath the ship but coherence drops below 0.5 at wavelengths less than $\sim 25$ $\mathrm{km}$.

However, significant longer wavelength differences between the magnetization solution and sample magnetization/geochemistry (e.g., $15-16^{\circ} \mathrm{S}$ ) must indicate either deficiencies in our characterization of the source layer geometry or unrecognized geochemical variability. For the region near 15$16^{\circ} \mathrm{S}$, substantial (factor 2) thinning of the extrusive source layer would be necessary to reconcile the magnetization solution and geochemical data. This is inconsistent with the increased thickness of Layer $2 \mathrm{~A}$ imaged seismically near the $15.9^{\circ} \mathrm{S}$ discontinuity (Fig. 2c). Moreover, a thicker effective magnetic source layer might be expected in this region from the modest deepening of the magma chamber and the lack of significant hydrothermal activity [27]. We conclude that in this $15-16^{\circ} \mathrm{S}$ region, sample 
geochemistry and magnetization values are unlikely to be representative of the average properties of the extrusive layer. We regard the anomaly data, which are sensitive to the magnetization of the entire extrusive layer, as the best available means for estimating the integrated degree of fractionation of the extrusive layer.

Our interpretation of the axial anomaly inversion also provides an indication of the thermal and magmatic supply along this portion of the southern EPR. Magmatic injection centers have been postulated to coincide with longer wavelength bathymetric highs $[6,28]$, with the least fractionated lavas erupted at the segment center and progressively more fractionated compositions towards the segment ends. Major element geochemical variations along some segments of the slow-spreading Mid-Atlantic Ridge [29] apparently support this model; however, it has been difficult to document any simple relationship between tectonic and magmatic segmentation at faster spreading ridges [7]. The difficulty in discerning coherent along-axis variations in the degree of fractionation is in part a function of the magnitude of within-dredge geochemical scatter (as high as $2-3 \% \mathrm{MgO}, 3-5 \%$ $\left.\mathrm{FeO}^{*} ;[5,30]\right)$ together with the minimal bathymetric relief on fast-spreading ridges.

The spatial integration inherent in sea surface magnetic anomalies provides an effective means of averaging local geochemical variability, allowing recognition of more subtle trends in the average degree of fractionation than is possible from surficial samples alone. The profile magnetization inversion solution from the southern EPR is characterized by a cuspate pattern, with the majority of the documented axial discontinuities with more than $2 \mathrm{~km}$ offset and even some smaller offsets accompanied by a corresponding magnetization high (Fig. 2). The dominant wavelengths of these variations (50-200 km) lie well within the band of high coherence between the axial anomaly and crustal magnetization [26]. Finer scale variations have in fact been filtered out during the inversion (Fig. 2 caption). Thus, magnetization changes due to local variation in the geometry of the source layer $[19,22]$ will not be discernible in the inversion solution.

On the basis of surficial sampling along the southern EPR, Sinton et al. [8] recognized five segments of relatively smoothly varying indices of fractionation superimposed on the secondary magmatic segmentation delineated by similarities in parental lava compositions. Boundaries of these five segments were poorly correlated with physical ridge axis discontinuities, leading Sinton et al. to conclude that the degree of differentiation was independent of magma supply, as indicated by axial depth or width (see Fig. 2c). In contrast, our magnetization solution indicates that many of the regions of smoothly varying $\mathrm{MgO}$ (and thus $\mathrm{FeO}^{*}$ ) contents identified by Sinton et al. [8] (e.g., between $23^{\circ} \mathrm{S}$ and $20.7^{\circ} \mathrm{S}$ ) apparently comprise multiple segments characterized by enhanced degrees of differentiation at ridge axis discontinuities. Although additional factors (e.g., oxygen fugacity, magma chamber size, hydrothermal cooling) may also be important, the close association between degree of differentiation and tectonic segmentation evident from the data in Fig. 2 suggests that the average degree of differentiation may indeed be strongly influenced by magma supply.

The substantial axial magnetization contrasts evident in the inversion solution, presumably related to geochemical variations along axis, imply that magnetic anomalies orthogonal to the ridge axis (referred to here as magnetic corrugations) might be expected from relatively long-lived variations in geochemistry. For example, Batiza et al. [30] documented a nearly constant degree of fractionation in N-MORB samples along two flowlines (to $\sim 0.8 \mathrm{Ma}$ ) at magmatically robust locations on the EPR near $10^{\circ} \mathrm{N}$ and large, systematic variations in geochemistry away from the magmatically starved part of the axis near $10^{\circ} 30^{\prime} \mathrm{N}$. The inferred constant or slowly varying average composition for the magma lens [30] should produce consistent geochemical, and hence magnetization and magnetic anomaly, patterns along a flowline although small scale spatial/temporal geochemical variations may also be present [31]. Iron enrichments near large offset axial discontinuities already have been suggested to be associated with magnetization highs at a high angle to the ridge crest that can be traced across the Central Anomaly in the northern EPR [32] as well as the southern EPR [33$35]$. Existing magnetic surveys $(5-8 \mathrm{~km}$ line spacing) near the axis of the southern EPR [18] arguably provide evidence that even some finer scale magnetization contrasts evident in the axial profile extend for tens of kilometers. Additional detailed magnetic 
surveys in this area that take better account of diurnal field variations may eventually reveal magnetic corrugations along spreading flowlines in addition to the ridge parallel lineations (tiny wiggles) commonly observed within constant polarity intervals [36].

The correspondence between magnetic anomaly amplitude and iron content documented here suggests that more detailed magnetic surveys are likely to be a valuable tool for assessing along axis changes in the average degree of differentiation of the extrusive layer. The presence (or absence) of magnetic corrugations elsewhere should provide limits on the temporal scales of fluctuations in average geochemistry. Moreover, we suggest that the spectral characteristics of high resolution magnetic anomaly data, particularly those collected nearer the magnetic source, may prove useful in evaluating the spatial scales of geochemical heterogeneity within the crust.

\section{Acknowledgements}

We thank J. Sinton and J. Mahoney for providing geochemical data and access to the southern EPR dredge collection. J. Mutter, J. Orcutt, R. Detrick and E. Hooft kindly provided access to the e9102 data. We are indebted to S. Cande, J. Natland, H. Staudigel, P. Castillo, S. Carbotte, M. Cormier, M. Perfit and especially R. Parker for many helpful discussions and advice on the analysis of axial magnetic anomaly data. D. Scheirer, P. Vogt, K. Macdonald, R. Batiza and an anonymous reviewer provided helpful reviews. D. Wilson provided additional comments. Support for this work was provided through the Marine Geology and Geophysics program of NSF (OCE94-02307, OCE9416839, OCE95-03916). Lamont-Doherty Earth Observatory contribution \#5836. [CL]

\section{References}

[1] P.R. Vogt, G.L. Johnson, Magnetic telechemistry of oceanic crust?, Nature 245 (1973) 373-375.

[2] J.C. Sempere, High-magnetization zones near spreading center discontinuities, Earth Planet. Sci. Lett. 107 (1991) 389-405.

[3] D.M. Christie, J.M. Sinton, Evolution of abyssal lavas along propagating segments of the Galapagos spreading center,
Earth Planet. Sci. Lett. 56 (1981) 321-335.

[4] J.M. Sinton, D.S. Wilson, D.M. Christie, R.N. Hey, J.R. Delaney, Petrologic consequences of rift propagation on oceanic spreading ridges, Earth Planet. Sci. Lett. 62 (1983) 193-207.

[5] J.M. Sinton, R.S. Detrick, Mid-ocean ridge magma chambers, J. Geophys. Res. 97 (1992) 197-216.

[6] J.A. Whitehead Jr., H.J.B. Dick, H. Schouten, A mechanism for magmatic accretion under spreading centres, Nature 312 (1984) 146-148.

[7] C.H. Langmuir, J.F. Bender, R. Batiza, Petrological and tectonic segmentation of the East Pacific Rise, $5^{\circ} 30^{\prime}-14^{\circ} 30^{\prime} \mathrm{N}$, Nature 322 (1986) 422-429.

[8] J.M. Sinton, S.M. Smaglik, J.J. Mahoney, K.C. Macdonald, Magmatic processes at superfast spreading mid-ocean ridges: glass compositional variations along the East Pacific Rise $13^{\circ}-23^{\circ} \mathrm{S}, \mathrm{J}$. Geophys. Res. 96 (1991) 6133-6156.

[9] P.R. Vogt, Amplitudes of oceanic magnetic anomalies and the chemistry of oceanic crust: synthesis and review of 'magnetic telechemistry', Can. J. Earth Sci. 16 (1979) 2236-2262.

[10] D.S. Wilson, R.N. Hey, History of rift propagation and magnetization intensity for the Cocos-Nazca spreading center, J. Geophys. Res. 100 (1995) 10041-10056.

[11] R.S. Detrick, W.S. Lynn, The origin of high-amplitude magnetic anomalies at the intersection of the Juan de Fuca Ridge and Blanco Fracture Zone, Earth Planet. Sci. Lett. 26 (1975) 105-113.

[12] J.-C. Sempere, K.C. Macdonald, S.P. Miller, Overlapping spreading centers: 3-D inversion of the magnetic field at $9^{\circ} 03^{\prime} \mathrm{N}$ on the East Pacific Rise, Geophys. J. R. Astron. Soc. 79 (1984) 799-811.

[13] S.P. Miller, R.N. Hey, Three-dimensional magnetic modeling of a propagating rift, Galapagos $95^{\circ} 30^{\prime} \mathrm{W}, \mathrm{J}$. Geophys. Res. 91 (1986) 3395-3406.

[14] N.D. Watkins, Magnetic telechemistry is elegant but nature is complex, Nature 251 (1974) 497-498.

[15] J. Gee, D.V. Kent, Magnetization of axial lavas from the southern East Pacific Rise $\left(14^{\circ}-23^{\circ} \mathrm{S}\right)$ : geochemical controls on magnetic properties, J. Geophys. Res. 102 (1997) 24873-24886.

[16] M. Marshall, A. Cox, Magnetism of pillow basalts and their petrology, Geol. Soc. Am. Bull. 82 (1971) 537-552.

[17] K.H. Rubin, J.D. Macdougall, Dating of neovolcanic MORB using $\left({ }^{226} \mathrm{Ra} /{ }^{230} \mathrm{Th}\right)$ disequilibrium, Earth Planet. Sci. Lett. 101 (1990) 313-322.

[18] R.S. Detrick, A.J. Harding, G.M. Kent, J.A. Orcutt, J.C. Mutter, P. Buhl, Seismic structure of the southern East Pacific Rise, Science 259 (1993) 499-503.

[19] G.M. Kent, A.J. Harding, J.A. Orcutt, R.S. Detrick, J.C. Mutter, P. Buhl, Uniform accretion of oceanic crust south of the Garrett transform at $14^{\circ} 15^{\prime} \mathrm{S}$ on the East Pacific Rise, J. Geophys. Res. 99 (1994) 9097-9116.

[20] G.M. Smith, S.K. Banerjee, Magnetic structure of the upper kilometer of the marine crust at Deep Sea Drilling Project Hole 504B, Eastern Pacific Ocean, J. Geophys. Res. 91 (1986) 10337-10354. 
[21] E.E.E. Hooft, R.S. Detrick, G.M. Kent, Seismic structure and indicators of magma budget along the southern East Pacific Rise, J. Geophys. Res. 102 (1997) 27341-27354.

[22] S.M. Carbotte, J.C. Mutter, L. Xu, Contribution of volcanism and tectonism to axial and flank morphology of the southern East Pacific Rise, $17^{\circ} 10^{\prime} 17^{\circ} 40^{\prime} \mathrm{S}$, from a study of layer 2A geometry, J. Geophys. Res. 102 (1997) 1016510184.

[23] D.R. Toomey, G.M. Purdy, S.C. Solomon, W.S.D. Wilcock, The three-dimensional seismic velocity structure of the East Pacific Rise near latitude 9³0'N, Nature 347 (1990) 639645.

[24] G.L. Christeson, G.M. Purdy, G.J. Fryer, Structure of young upper crust at the East Pacific Rise near $9^{\circ} 30^{\prime} \mathrm{N}$, Geophys. Res. Lett. 19 (1992) 1045-1048.

[25] R.L. Parker, S.P. Huestis, The inversion of magnetic anomalies in the presence of topography, J. Geophys. Res. 79 (1974) 1587-1593.

[26] R.L. Parker, Inversion of on-axis magnetic anomalies, Geophys. J. Int. in press.

[27] T. Urabe et al., The effect of magmatic acitivity on hydrothermal venting along the superfast-spreading East Pacific Rise, Science 269 (1995) 1092-1095.

[28] H. Schouten, K.D. Klitgord, J.A. Whitehead, Segmentation of mid-ocean ridges, Nature 317 (1985) 225-229.

[29] R. Batiza, W.G. Melson, T. O’Hara, Simple magma supply geometry inferred beneath a segment of the Mid-Atlantic Ridge, Nature 335 (1988) 428-431.

[30] R. Batiza, Y. Niu, J.L. Karsten, W. Boger, E. Potts, L. Norby, R. Butler, Steady and non-steady state magma chambers below the East Pacific Rise, Geophys. Res. Lett. 23 (1996) 221-224.

[31] M.R. Perfit, D.J. Fornari, M.C. Smith, J.F. Bender, C.H. Langmuir, R.M. Haymon, Small-scale spatial and temporal variations in mid-ocean ridge crest magmatic processes, Geology 22 (1994) 375-379.

[32] S. Carbotte, K. Macdonald, East Pacific Rise $8^{\circ}-10^{\circ} 30^{\prime} \mathrm{N}$ : Evolution of ridge segments and discontinuities from SeaMARC II and three-dimensional magnetic studies, J. Geophys. Res. 97 (1992) 6959-6982.

[33] L.J. Perram, M.-H. Cormier, K.C. Macdonald, Magnetic and tectonic studies of the dueling propagating spreading centers at $20^{\circ} 40^{\prime} \mathrm{S}$ on the East Pacific Rise: evidence for crustal rotations, J. Geophys. Res. 98 (1993) 13835-13850.

[34] K.C. Macdonald, R.M. Haymon, S.P. Miller, Deep-Tow and Sea Beam studies of dueling propagating ridges on the East Pacific Rise near 2040'S, J. Geophys. Res. 93 (1988) 2875-2898.

[35] M.-H. Cormier, K.C. Macdonald, East Pacific Rise $18^{\circ}-$ $19^{\circ} \mathrm{S}$ : Asymmetric spreading and ridge reorientation by ultrafast migration of axial discontinuities, J. Geophys. Res. 99 (1994) 543-564.

[36] J. Gee, D.A. Schneider, D.V. Kent, Marine magnetic anomalies as recorders of geomagnetic intensity variations, Earth Planet. Sci. Lett. 144 (1996) 327-335.

[37] D.S. Scheirer, K.C. Macdonald, Variation in cross-sectional area of the axial ridge along the East Pacific Rise: evidence for the magmatic budget of a fast spreading center, J. Geophys. Res. 98 (1993) 7871-7885. 